\title{
Stress in nurses in Intensive Care Units
}

\section{ESTRESSE EM ENFERMEIROS DE UNIDADES DE TERAPIA INTENSIVA}

Rosemeire de Jesus Ferreira Leitão ${ }^{1}$, Janayna Thainá Rabelato ${ }^{2}$, Wanderley Marques Bernardo ${ }^{3}$

${ }^{1}$ Coordinator of the nursing program at the Lusíada University Center - UNILUS.

${ }^{2}$ Medicine Undergraduate Student at the Lusíada University Center - UNILUS.

3PhD-Professor at the do Lusíada University Center - UNILUS.

\section{Objective}

To assess the level of stress, and associated activities in nurses working in the Intensive Care Unit.

\section{Methods}

Prospective cross-sectional study to answer the following questions: is the stress level of nurses working in ICU high? Is there a relationship between stress and working conditions? Which of the activities of nurses generate more stress?

The population consisted of 71 nurses working in ICUs, distributed in 6 hospitals. Data collection was performed using the Bianchi questionnaire, ${ }^{1}$ based on the 51 -item total stress score for nurses, including the relationship with other units and superiors (A), activities related to the unit's proper functioning (B), staff administration (C), nursing care provided to the patient (D), unit coordination (E) and working conditions $(\mathrm{F})$. The total score value has a variation of 51 points (when the nurse classifies all activities as stressful) and 357 points (when the nurse classifies all activities as very stressful), resulting in the average value between 1 and 7. Levels obtained were classified into low (equal to or less than 3), moderate (3.1 to 5.9) and high (equal to or greater than 6) levels of stress.

\section{RESULTS}

Regarding general data, the majority were female (74.64\%), aged $31-40$ years $(46.67 \%)$, married (53.5\%), with children (59.15\%). 61.97\% of these nurses do not have another job and $60.56 \%$ work 12 -hour shifts. Regarding training time, $38.02 \%$ had work experience of two to five years and $84.5 \%$ of respondents had graduate degree diplomas.
The average stress of these nurses reached a score of 3.87 , which according to the reference values is equivalent to a moderate stress level. The highest stress score was 4.27, and the lowest stress score of 3.36. There was no significant difference between hospitals $(\mathrm{p}=0.65)$.

In terms of score distribution among hospitals, 49 nurses (69.01\%) show moderate levels, 20 nurses $(28.16 \%)$ have low levels, and 2 nurses (2.81\%) have high levels of stress.

There was no significant difference in the level of stress in relation to gender, age, dual employment, working hours, training time and graduate degree.

Regarding domains, personnel administration (C) showed a higher stress score. Performing activities with minimal time available was the most stressful activity $(F)$. Nursing care provided to the patient (D) showed a higher number of stress-generating activities.

\section{Conclusion}

Regardless of the results of this study, it is important to establish parameters to systematically measure the stress level of health professionals involved in care or administrative activities. The stress level of nurses in this study or in other samples may indicate specific areas to receive interventions aiming at improving performance and quality of patient care.

\section{Reference}

1. Bianchi ERF. Escala Bianchi de stress. Revista da Escola Paulista, São Paulo, v. 43, p.1055 - 1062, 2009. 